\title{
The Impact of Servant Leadership on Innovative Work Behavior in Ghana: The Mediation of Employee Voice
}

\author{
Edward Kofi Krupah \\ College of Economics and Management, Nanjing University of Aeronautics and Astronautics, \\ Nanjing-21106, China \\ E-mail: edwardkrupah@yahoo.com \\ Benedicta Afia Boatemaa Krupah \\ Collegium Civitas University, 00-901 Warsaw, Poland \\ krupahbenedicta@yahoo.com
}

\begin{abstract}
Innovation is a crucial concept for organizational sustenance and development. The study investigated the impact of servant leadership on employee innovative work behavior by examining the mediating role of employee voice in Ghana. This was done to contribute to fostering innovation in the nation and stimulate the idea of servant leadership behavior in Ghanaian organizations where generally, power appears to be distant.Data from 200 fulltime Ghanaian workers were used in this cross-sectional study. Pearson's correlation, linear regression, and SEM were utilized in the data analysis. The empirical findings from the study demonstrate that servant leadership and employee voice correlate significantly and positively with innovative work behavior. However, employee voice failed to mediate the effect of servant leadership on employee innovative work behavior. Servant leadership in Ghana also failed to exert positive influence on employee voice.The implication of this research infers that organizational leaders in Ghana can have confidence in putting on servant leadership behavior to increase innovative work behavior in employees as is critical for organizational productivity and survival. The deliberate attempt to augment innovation also means that organizations necessitate the intentional creation of atmospheres (climate for innovation) for breeding and nurturing practical, innovative concepts. This study also gives employers the assurance that encouraging employee voice in the workplace is critical since it keeps the lines of communication open and serves as a deterrent to operational behaviors that hamper organizational advancement. The study further elaborates a detailed discussion of the research results, implications, limitations, and prospects for future studies.
\end{abstract}

Keywords: Servant leadership, innovative work behavior, employee voice, Ghana

DOI: $10.7176 / \mathrm{EJBM} / 14-2-08$

Publication date: January $31^{\text {st }} 2022$

\section{Introduction}

Innovation, by implication, innovative performance and work behavior is central to organizational development. Organizations in Ghana pursue innovation for many reasons. Some of the key driving factors for innovation is to enhance the financial, marketing, product, and service performance of enterprises. This helps organizations in the retention of clients and the attraction of new ones to ensure profitability and sustainable continuity of service delivery. Furthermore, it provides organizations with a competitive edge necessary for long-term survival in Ghana's free-market system (Oduro \& Nyarku, 2018). Recent studies on innovation discovered that innovation was positively associated with organizational productivity (Nair et al., 2011; Oduro \& Nyarku, 2018; YuSheng \& Ibrahim, 2020). YuSheng \& Ibrahim (2020) in their study revealed a positive relationship between innovations and banking performance in Ghana's financial sector. Under the "One World No Hunger" initiative, the agricultural industry has employed innovative strategies for sustainable agricultural growth that aim to promote agricultural innovation, improve food and nutrition security, and build sustainable value chains in the agri-food sector in Ghana and across other African nations. (Sanda \& Arthur, 2017). Similar studies like that of Arthur (2016) also investigated the influence that authentic and transactional leadership styles sustain on employee creativity (a vital component of innovation) in Ghana's telecommunication industry.

Among many popular leadership styles broadly studied as contextual factors influencing employee creativity and innovation, servant leadership has evolved as an interest for leadership scholars (Northouse, 2019). The revelation of servant leadership in this research is intended to unveil by way of providing significant empirical insight to stimulate the idea of servant leadership behavior in Ghanaian organizations where generally, power appears to be distant (Hale \& Fields, 2007). Often as observed, the prevalent servant-master relation that lacks cordiality and empathy influenced by high power-distant organizational culture in Ghana dictates what organizations want from employees and does not so much emphasize how much employees can and have to offer in the promotion of innovational concepts.

To a much larger extent, organizational leadership in Ghana has been described as paternalistic (AsieduAppiah F., Agyapong A., 2017). Paternalistic leadership is based on the traditional belief that the leader has the 
authority to make decisions and that their legitimacy stems from their level of knowledge, achievements, and expertise. The leader has the final word in decision-making, and there is no need for consultation because the leader is assumed to make decisions that should benefit the entire organization (Leunendong, 2020). However, this way of management has limitations as far as the administration of organizational affairs is concerned (StudiousGuy, 2021). Although paternalistic leadership is recognized to empower employees as a father would want to see his son or daughter grow and succeed; nevertheless, it does not give employees authority in decisionmaking. Employee morale can be negatively affected due to their non-participation in organization decisionmaking because it creates a psychological limitation (low psychological safety) that constrains employee voice (StudiousGuy, 2021).

For this reason, employees might not value or see themselves fit to make recommendations to contribute to organizational success. Another limitation is that subordinates tend to depend on the leader for every decision needed for organizational progress, which can slow the company down, especially when the leader is unwell or unavailable for an unfortunate reason. This state of leader dependency does not allow for proper employee empowerment, giving employees the opportunity to handle specific work-related issues in a way that employees see fit as their education, skills, and expertise would allow (Leunendong, 2020).

With these cumulative experiences, employees, in the long run, might also begin to feel incompetent and less inclined to find and discover new solutions to problems that may arise in the organization affecting their ability to be innovative. This type of leadership may not be the best for organizations in Ghana because it does not display much trust in employees' ability to perform independently. This, in effect, can limit employee aptitude to be innovative on the job, bringing about diminishing returns to organizations because they fail to utilize their workforce to the best of their abilities. The paradox is that it remains an undebatable fact that employees play a critical role in introducing innovative outputs in organizations necessary for organizational development (Shafi et al., 2020). In this age of educated, proactive, and vibrant millennials who are eager to develop, grow and make an impact, a platform that supports their growth and takes a keen interest in their professional or personal development whiles furnishing them with the opportunity to express their expertise through the introduction of innovative ideas and the implementation of the same is what they require. This is intended for both employee and organizational development.

Convincingly, as important as employee innovative work behavior is, the import of leadership as a contextual factor can predict to an enormous degree to which employees can be innovative (Kremer et al., 2019; Scott \& Bruce, 1994; Shalley et al., 2004). Maxwell (2007) in his book, "the 21 irrefutable laws of leadership" reiterated that "Everything rises and falls on leadership." Employee innovative behavior can be limited or augmented depending on the type of leadership supervising or managing them. For this reason, researchers have endorsed leadership behavior that is people-centered, lays emphasis on social contribution, and looks out for employee welfare rather than the glorification of the leader (Barbuto \& Wheeler, 2006; Laub, 2004; Northouse, 2019). On this proposition, servant leadership has emerged as one of the preferred leadership styles known for its selfless attribute of placing followers first, sharing power and emphasizing follower growth and success.

However, descriptive studies on servant leadership and its influence on innovation and employee voice over the decade has focused primarily on Western and Asian cases, depriving the scholarly community of other different demographic viewpoints (Li et al., 2021; Ruiz-Palomino \& Zoghbi-Manrique-de-Lara, 2020; Yan \& Xiao, 2016; Yoshida et al., 2014). Therefore this research aims to bridge the gap by investigating its impact within a Ghanaian context; hence contributing to literature on this vital topic. This will provide researchers with a more holistic view of the effect of servant leadership on employee voice and innovative work behavior.

Finally, employee innovation requires the communication of creative ideas. Before an idea can be implemented as an innovative outcome, it first has to be transported from the realm of one's imagination through communication. Therefore the examination of employee voice in this research is to establish the relationship servant leadership in Ghana has with employee voice behavior whiles also considering its influence on innovative work behavior. One way to identify the quality of the relationship between employees and managers/supervisors is by determining the quality of their interaction on the job (Dyne \& LePine, 1998). Therefore, it is also the goal of this study to investigate the impact of servant leadership on innovative work behavior by examining the mediation of employee voice. Communication, as examined through employee voice, requires that leaders augment their ability to create atmospheres and avenues for effective communication to occur; whiles striving to sustain a healthy leader-member relationship by encouraging a healthy vertical dyad between managers and employees (Erdogan \& Bauer, 2015). This is because the tolerance of employee voice can influence employee innovative behavior, and productivity at the workplace and serves as a significant way of communicating creative intentions leading to innovation (Kremer et al., 2019). The discovery of this study would also add to current literature on employee voice behavior, as touching an economy where very little empirical research has been carried.

The next section of this article outlines the theoretical background of the research variables and develops hypothesis to test them based on the study's conceptual model. After that, it emphasizes and elaborates on the 
research methodology and reports the empirical results. Following, the results are discussed along with the research's implication, limitations and potential prospects for future studies. Lastly, the article ends with a research conclusion.

\section{Theoretical Background 2.1 Servant Leadership}

Hale \& Fields (2007) discovered compatibility of servant leadership within the framework of Ghanaian organizational culture in an exploratory study to determine whether or not servant leadership was a western concept or could also be applied to an African context. Their assessment showed that servant leadership behavior was higher in the USA as their culture was characterized by a relatively low power distance and a low tolerance for ambiguity than Ghana. With many similar exploratory and empirical scholarly research, servant leadership has progressed as an area of research importance for leadership scholars in the last ten years. This concept of leadership appears paradoxical because it manifests not to be what many perceive leadership to be according to the conventional way. Before Greenleaf coined the term "servant leadership" history has records of men who traversed the face of the earth demonstrating servant leadership behaviors and characteristics. After tapping into the inspirational and gracious life of Jesus Christ of the Christian Bible, who is believed to be the greatest leader of all time, lived not to be served but to lovingly serve others for their deliverance, freedom, and ultimately to reconcile them to a harmonious fellowship with the one and only true God of the universe. According to historical records he served even to the point of dying for his followers and was resurrected on the third day. Whoever believes in him shall be saved from sin and the corruption in this world as he grants his followers eternal life to live a life of love with him even to this day for eternity. This is because he recognizes that love is the greatest need of the human race. And leaders who truly loves their followers will serve them for their good and the benefit of all. Napoleon Bonaparte allegedly said about Jesus Christ in quote, "I know men and I tell you that Jesus Christ is no mere man. Between Him and every other person in the world there is no possible term of comparison. Alexander, Caesar, Charlemagne, and I have founded empires. But on what did we rest the creation of our genius? Upon force. Jesus Christ founded His empire upon love; and at this hour millions of men would die for Him. "(Nugent, 2018). History also consider men like Nelson Mandela, the late President of South Africa who endured much hardship and suffering for service for his country-men for their liberation from apartheid (Blakemore, 2020).

Robert Greenleaf however developed the seminal work of servant leadership and credited his formulation of the servant leader to Hermann Hesse's novel "The journey to the East" (Peter G. Northouse, 2019). A story of a mythical journey embarked on by a group of travelers, with a servant who serves and sustains them on the journey. Greenleaf's referenced definition of servant leadership: "[Servant-Leadership] begins with the natural feeling that one wants to serve, to serve first. Then conscious choice brings one to aspire to lead. . . The difference manifests itself in the care taken by the servant first to make sure that other people's highest priority needs are being served. The best test ... is: do those served grow as persons; do they, while being served, become healthier, wiser, freer, more autonomous, more likely themselves to become servants? And, what is the effect on the least privileged in society; will they benefit, or, at least, will they not be further deprived?" (Northouse, 2019).

The historical basis for servant leadership was formulated to address challenges of power and authority associated with coercive leadership, focusing instead on how organizations could creatively help one another serve society successfully. Servant leadership has been discovered to resonate with many people as an excellent method to operate a business (Northouse, 2019). Greenleaf (1970) writes that a servant leader has a social responsibility to care about the "have-nots" and those ostensibly less fortunate. A servant leader is also one who eliminates or attempts to eliminate existing inequalities and social injustices. Servant leadership theory has emerged as a distinct leadership concept that prioritizes followers. According to this theory, the most powerful leaders are servants of their people. Greenleaf also posits that this type of leadership gives individuals the opportunity to experience interdependence, individual growth, trust, and respect (Northouse, 2019).

Another leadership style, such as traditional leadership, focuses on how top-level managers influence employees lower in the organizational hierarchy, whereas servant leadership focuses on and emphasizes collaboration (Burkus, 2010). As recorded in an interview with Rebecca Herman, a professor and an expert in organizational culture, noted that "traditional leadership emphasizes financial performance, goals, strategy, and customer satisfaction." "Those things are not bad, of course," she utters. "Those are things we expect leaders to do. We want our CEO to focus on things that are going to bring us profit. "But servant leaders go further. They focus on providing their employees with development opportunities. Employees today want to feel they have a job where they can succeed. They want an opportunity to be coached and mentored by someone"'" (Purdur, 2020). Furthermore, because servant leaders prioritize people, they get to know them on a deeper level. They assist them in developing and providing opportunities because they empower them rather than micromanaging them.

The coercive leadership style, where power tends to be very distant, emphasizes employees executing orders with immediate and absolute compliance (Miller, 2021). Servant leadership, on the other hand, focuses on power- 
sharing, in which employees are encouraged to be autonomous in carrying out their job duties in order to grow. According to this theory, if leaders focus on meeting the needs and requirements of their followers, this should have a multiplier effect in that employees will perform better, become more engaged, and increase teamwork, thereby promoting organizational productivity (Greenleaf, 1970). Northouse (2019) presented a servant leadership model based on Liden et al. (2008), which reveals that servant leadership positively affects follower performance and growth, organizational performance, and societal impact.

Spears (2002) explored ten characteristics of servant leadership as to help us understand what it entails. They include, "listening, empathy, healing, awareness, persuasion, conceptualization, foresight, stewardship, commitment to the growth of people, and building a community" (Northouse, 2019). Similarly Liden et al. (2015) identified seven significant dimensions of servant leadership, namely: conceptualizing, which describes the capacity that allows servant leaders to think through complex and nuanced problems, recognize when something is wrong, and solve issues constructively in accordance with the company's core goals; emotional healing, which is the servant leader's responsiveness to the specific concerns and betterment of others; putting followers first, which deals with the servant leader's actions and utterances that make evident to followers that their concerns are a top priority. This also includes placing followers' interests and success ahead of the leader's; helping followers grow and succeed, which requires knowing followers' professional or personal goals and assisting them in achieving those goals; behaving ethically, which necessitates the servant leader appropriately does the right thing; and empowering which constitutes building followers' assurance in their own capability to reason and act on their own as they are given the liberty to handle problematic situations in the way they feel is best appropriate. Finally, servant leaders contribute to the development of communities by giving back to it knowingly and intentionally." (Northouse, 2019).

\subsection{Innovative work behavior}

Jong \& Hartog, (2008) defined innovative work behavior as 'an individual's behavior that aims to achieve the initiation and intentional introduction (within a work role, group or organization) of new and useful ideas, processes, products or procedures as well as the implementation of those ideas".

Innovative work behavior, according to Jong \& Hartog, (2008) constitutes of four distinctive dimensions. These include "idea exploration, which involves the discovery and identification of opportunities, problems, and complex puzzles arising in an organization that needs to be solved to improve working conditions or avert potential threats that may cause operational problems to organizational functional". Second on the scale is "idea generation, which takes account of the construction of new ways to solve an issue; this is to improve and enhance working procedures, processes, products, and services or gain entry into new markets to expand organizational operations". "A third of the process is "idea championing; this factors one's ability to successfully pitch and sell a novel idea, form coalitions and gain support from colleagues and senior management staff; this is needed in overcoming opposition granting one the advantage of persuading influential personnel in an organization." Last of the process is "idea implementation; which necessitates that one has a result-oriented attitude to transform an idea into a practical, workable product, service, or new procedure that sustains the capacity to enhance organizational performance" (J. P. J. D. Jong \& Hartog, 2008; Krupah, 2021).

\subsection{Voice behavior}

Voice is defined as "an individuals' voluntary and open communication directed toward individuals within the organization that is focused on influencing the context of the work environment" (Maynes \& Podsakoff, 2014). Employee voice behavior comprises of two dimensions, namely, promotive voice which is defined as "employee expression of new ideas or suggestions for improving the overall functioning of their work unit or organization"; and prohibitive voice, "describing an employees' expressions of concern about work practices, incidents, or employee behavior deemed harmful to their organization"(Dyne \& LePine, 1998). However, this research looks at supervisors' rating of employee voice behavior as an integrated unit.

\subsection{Conceptual Model}

The underlying logic behind the conceptual model of this study is grounded on social exchange theory (Redmond, 2015) which reasons that a relationship between two distinct persons is formed through a process of cost-benefit analysis and therefore determines how much effort an individual expends or puts into a person to person association. On this premise, the research model posits that employee innovative work behavior is a function of servant leadership behavior, and employee voice. This conceptualized framework demonstrates that the behavioral disposition of leaders as they interact with employees daily sustains sufficient influence on employee voice behavior and employee innovative work behavior. Therefore, leaders who take on servant leadership behavior possess suitable attributes and initiatives, including the deliberate actions taken to help followers grow and succeed, granting employees a supportive contextual system needed to stimulate innovation in Ghana. The model further expresses that servant leadership would influence employee voice, which would serve as a critical 
antecedent to innovative work behavior. Before an innovative idea can be implemented, it, first of all, has to be communicated. Therefore the extent to which employees are able to communicate innovative ideas that may enhance organizational performance can be expressed by voice.

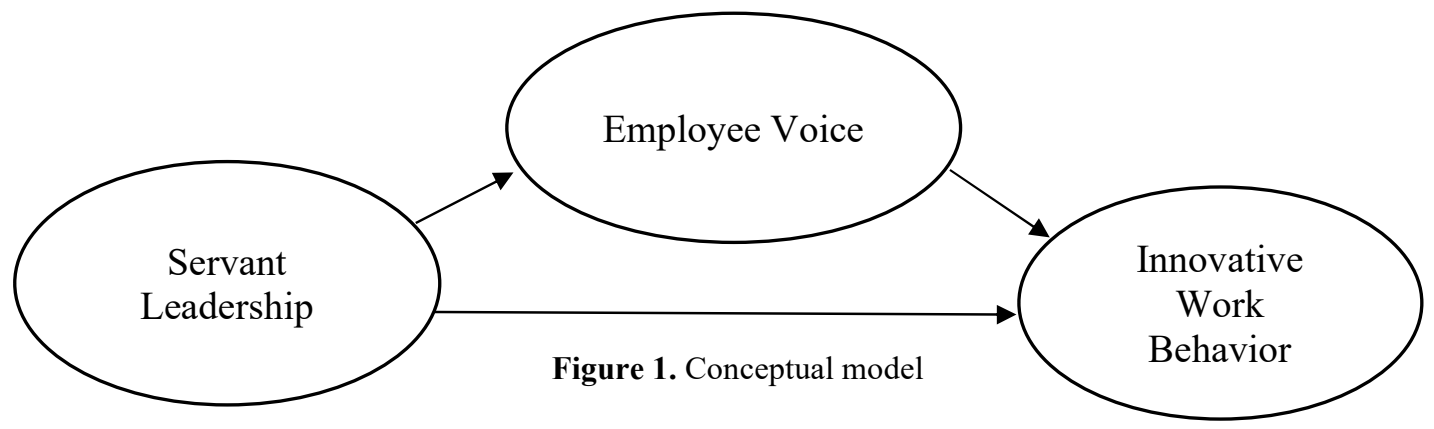

\subsection{Hypothesis Development}

2.5.1 Servant leadership and innovative work behavior

In aiding and effecting organizational expansion and progress, leaders help run and implement strategic organizational structures and policies that are perceived as advantageous towards the development of individuals and organizations. Over the centuries, leaders have acted as catalysts to initiate, spearhead, and influence people towards achieving the desired organizational goal. Leadership can also play a significant role in either fueling or suppressing employee innovation. The relationship between leadership and employee creative performance has been a subject that researchers over the years have comprehensively examined. Leadership behavior is classified as one of the contextual factors influencing employee creativity and innovation. Many scholarships have identified different degrees of correlations existing between various leadership approaches and their corresponding effect on employee innovative performance and work behaviors (Kremer et al., 2019; Lee \& Kim, 2021; Müceldili et al., 2013). As it remains an area of growing academic interest, this literature serves as an impetus for the study to investigate the relationship in an economy where very little empirical research has been conducted on servant leadership and its underlying influence on creative performance.

In as much as relative individual characteristics such as personality and different cognitive styles have been discovered to play a significant key role in determining and influencing employee's ability to perform creatively and innovatively on the job (Amabile, 1996; Shalley et al., 2004; Woodman, 1993) the import of leadership behavior is another critical aspect that cannot be overruled. A study conducted in the telecommunication sector in Ghana by Sanda \& Arthur (2017) asserted that authentic leadership style positively impacted employee creativity by implication innovative work behavior.

Servant leadership is a positive leadership style that exudes supportive manifestations inspiring innovative behaviors as it encourages and motivates employees to be expressive in displaying innovative ideas and implementing them during work processes. Servant leaders can immensely foster creative performance as they allow employees to actively engage in activities that generate, explores, and champion ideas capable of breaking organizations through difficult times. When leaders have and show confidence in their subordinates, it creates an environment that embraces diversity and innovation, and these are two vital proponents that can cause organizations to thrive and succeed in their adventure to become the best version of themselves and surmount every obstacle with ease. Many organizations and economies that are held back today struggle because of the lack of innovative ideas that sustain enough force to catapult them to a higher height and this is partly accrued to the consequence of leaders not placing any or showing very little confidence in their workforce thereby suppressing employee innovative work behavior.

Uniquely, as opposed to many leadership practices, one of the core attributes of a servant leader is that he/she puts followers first. This communicates genuine interest displayed toward employee growth and success, sustaining the capacity to activate and unlock creative potential that may have been dormant or inhibited by various vicissitudes of life. When an employee needs to facilitate their growth are met, and supervisors show unpretentious concern for their wellbeing in serving them, it gives employees a tangible reason to reciprocate by performing at their best (Eva et al., 2019) once they perceive how much their leaders care for them, making their professional development and psychological wellbeing their priority. This is also in accordance with the social exchange theory.

Furthermore, another important characteristic of a servant leader is seen in his/her ability to behave ethically towards work, colleagues, and subordinates. A servant leader is one who would not compromise value and process for results. In their dealings with employees, this communicates integrity and helps employees build trust and confidence in them. Employees in such regard can communicate novel ideas with leaders that may be beneficial 
to organizational growth without fear of being penalized. When employees are treated with modesty, and equity, eventually this translates to birth and ignites in them the drive to perform diligently in executing their work duties putting in the necessary efforts to ensure that organizational goals and objectives are met just as their psychological contracts are met. According to the social exchange theory, this can lead to a cycle of cheerful service and performance from the employee's side as a response to the effect of being supported and treated with fairness by supervisors.

An essential tenet of a servant leader is seen in his/her ability to empower followers. Servant leaders do this by giving employees significant autonomy to do their work in the way they feel. This motivates employees to search out new working methods and generate original solutions to problems they may encounter during work processes. Employees can also systematically introduce innovative ideas and approaches to execute their work.

Servant leader's also help followers grow and succeed. For this reason, they are able to encourage and assist employees in developing new things and implementing novel ideas to stir departmental or cooperate organizational growth. In doing this, servant leaders can induce a craving in employees, causing them to always wonder how things can be done differently to bring about dynamic transformations to foster innovative performances at the workplace. This study, therefore, expects servant leadership to positively impact employee innovative behavior, thereby leading to employee growth.

Hypothesis 1: Servant leadership will positively influence employee innovative work behavior.

2.5.2 Employee Voice and Innovative work behavior

Zhou and George (2001) observed employee creativity, a fundamental facet of innovation as an expression of voice. Because employee voice can deliver novel and intelligent ways of processing work activities, it is expected to foster innovative estimations. Employees can suggest new procedures to improve the operation of his or her working unit or department by using voice. By reason of employee's proximity and regular involvement with clients as frontline workers, employees can also positively suggest new ideas to improve the relationship between workers and clients. This enables them to gather tacit information around the job that could improve the services organizations render to customers to deliver new and contemporary ways and techniques for running business activities on a daily basis.

Employees can also advise their colleagues and management against undesirable behavior that could hamper innovative job performance. Additionally, through the engagement of voice, employees can proactively report coordination problems in the workplace to the management for the implementation of new procedures, thereby augmenting innovative performances. Employee voice seeks to address and avert potentially harmful practices or behaviors that could inhibit productivity and introduce better, profitable, and efficient ways of doing business.

It is worth noting that when employees conceive an innovative idea, it may be subjected to several bureaucratic stages for verification before the idea can be implemented. This is done for administrative purposes. Employee voice becomes necessary for the communication of these ideas with their colleagues and supervisors to get their view and support for the championing and implementation of the same. Avey et al. (2012) and Walumbwa et al. (2012) helped strengthen the position of voice behavior and its influence on employee innovativeness as the study unfolded that voice behavior related positively to employees' creative performance. Therefore, on the strength of these empirical findings, we can confidently predict that the supervisor's rating of employee voice will positively influence employee innovative work behavior.

Hypothesis 2: Employee voice will positively influence innovative work behavior

2.5.3 Servant Leadership and Employee Voice

The leadership duty to encourage and tolerate employee voice behavior has been recognized as making employees feel valued, granting them the notion and prospect for growth, thereby heightening their morale, engagement, and involvement at the workplace (Zhou, J. and George, 2001). This is especially occasioned when employee inputs resulting from critical, creative thinking are appreciated, evaluated, and perhaps implemented once proven to sustain the fortitude to improve workplace functionality (Amabile, 1983).

One of the distinguishing marks of a servant leader as asserted by Spears, (2010), is demonstrated in his/her ability to listen to followers. He further says that servant leaders communicate by listening first and through this discipline, acknowledging followers' viewpoints and validating their perspectives, displaying a disposition of open-mindedness towards constructive suggestions and concerns employees may have.

A recent study developed by Yan \& Xiao, (2016) asserts that servant leadership is positively related to voice behavior. Leadership behavior that reveals supportiveness and positivity positively correlates with employee voice behavior, while negative leadership does not. An empirical review conducted in a study posits that abusive leadership restrains employee voice (Frieder et al., 2015) whiles transformational leadership motivates voice behavior (Afsar et al., 2019; Detert \& Burris, 2007).

Voice behavior is an important phenomenon correlating with organizational performance (Walumbwa, F. O., Morrison, E. W., \& Christensen, 2012) as it reveals creative ideas, direction opinions, and thoughts and seeks to persuade people in organizations to implement these constructive suggestions (Frieder et al., 2015). Employee voice can be expressed through promotive or prohibitive voice behavior (Liang et al., 2012). In touching the 
antecedent of promotive and prohibitive voice behavior, Liang et al. (2012) posit that, felt obligation for constructive change, organizational self-esteem, and psychological safety where the motivation that determined the degree to which employees were willing to engage their voice in organizational affairs as this is critically influenced by leadership behavior.

Promotive voice behavior seeks to commend management practices, promote the status quo, and augment organizational performance through suggestions of ideas that may improve working procedures. This may well be related to the notion that best describes a state of employees' contentment and satisfaction with how an organization is being run yet seeks to make constructive contributions to positively influence work units to reach its goals. Through this behavior, employees derive a sense of motivation forceful enough to stimulate personal development and employee creative and innovative prowess. Leaders are appreciative when they receive positive feedback from their work initiatives leading to organizational progress. Consequently, this encourages the leader to be their best and give their best in developing and producing a workplace that causes everyone to thrive and deliver at their maximum capability.

On the contrary, prohibitive voice behavior seeks to challenge the status quo and correct organizational practices to improve it. This is demonstrated when employees proactively report coordination problems that occur in the workplace or speak honestly on issues of adverse behavior that may hamper work performance. However, this may have some level of risk attached to it because of the uncertainty involved in not being able to fully determine the nature of the reception of the message or predict the probability to which the employee would be misunderstood and tagged as arrogant and disrespectful (Detert, J.R. and Burris, 2007). An employee's decision to voice out in this manner can be related to the dissatisfied state of the employee as far as work progress is in view; therefore, voicing out for modifications to take place to enhance work practices. Cognitively when employees perceive that the associated risk or cost of voicing out is high due to an unsafe working climate occasioned by organizational tension or unhealthy disposition by the management, the likelihood of keeping quiet may be expected to be higher than the adverse option associated with the decision to speak out. The risk involved in voicing out could be detrimental to losing their job, experiencing a salary cut, and perhaps having a tarnished reputation before their supervisors, potentially depriving them of promotional prospects and other lucrative incentives and company benefits. Detert and Burris, (2007) recorded and noted that even the most proactive or satisfied employees are more likely to observe the wind as to whether it is innocuous and advisable to speak up in their particular context.

Furthermore, another stream of study emphasizes facets of organizational context that may expedite or impede employees' disposition to speak up. Periodically when certain employees recognize the risks accompanying voice behavior (Prohibitive voice), they may still voice out because of their uncompromising attitude towards upholding their moral standards, cultural and ethical values (Gentile, 2012). This is supposed to be understood to prevent a foreseen crisis or harm that may destabilize the work process.

With prohibitive voice behavior, Liang et al., (2012) write that good intention behind speaking out on potentially harmful factors may not be easily identified or discerned by supervisors or interpreted as positive because of the potential negative emotion and defensiveness attached in the process. When an employee's prohibitive voice is not received constructively or misunderstood, would this create problems? As a result of this, employees are encouraged to take a calculated risk towards their decision to speak out through their perceptive organs and be ready to bear the consequences or enjoy the gratification of their actions.

Notwithstanding, other tributaries of research have also explored the individual attributes, factors, mannerism, and behavior that influence employee voice behavior regardless. Van Dyne, \& LePine, (1998) asserted that extraversion, conscientiousness, agreeableness, and neuroticism are related to employee voice behavior. Nikolaou et al., (2007) also made some profound discoveries that two personality characteristics, i.e., emotional stability and conscientiousness, are ominously linked with employees' voice behavior towards their immediate supervisor, but not towards the company's top management. Based on these compounded empirical findings relating to servant leadership and voice behavior, we propose that servant leadership will positively influence employee voice.

Hypothesis 3: Servant leadership will positively influence employee voice

2.5.4 The Mediation of Employee Voice

Employees are important forces and resources to organizational advancement and therefore can determine the quality of organizational performance and innovativeness. One of the ways employees do this is through engaging voice (Kremer et al., 2019). Employee voice behavior can be promotive or prohibitive in nature; however, is it imperative for organizational leaders to come to the comprehension that the goal of employee voice per the context of this study is for organizational advancement and sustainable development and therefore their communication based on their witness or suggestions to improve organizational performance should be explained and analyzed from this perspective. Employee voice can mediate the relationship between servant leadership and innovative work behavior because, without the communication of creative and innovative ideas, the process of innovative work behavior cannot find formulation or construction (Zhang et al., 2013). Therefore, employee voice should be encouraged and entertained as a key variable in augmenting innovative work behavior for the ultimate benefit of 
increasing innovative outputs.

Employees use their voices to develop and make imports that may positively influence and improve the working procedures of organizations. Employee voice can also deliver constructive new suggestions to help organizations reach their goals. Consequently, employee voice can counsel colleagues and management staff against undesirable behavior that could hamper work performance or affect efficiency at the workplace. It can also be used to report coordination problems that can lead to severe loss to an organization and communicate better ways, procedures, and effective techniques for arriving at organizational innovation and therefore thwarting or overcoming problems that can hijack organizational progress, causing it to stagnate or retrogress (Liang et al., 2012; Maynes \& Podsakoff, 2014). Spears (2010) noted that servant leaders are listeners; for this reason, employees can be bold to share ideas that may be perceived as beneficial to organizational innovation because they know they would have a listening ear to what they wish to communicate. In arriving at innovation that is the successful introduction of creative outputs, employee voice can be used for persuasion, which is critical in championing ideas (J. De Jong \& Den Hartog, 2010), granting the employee the opportunity to pitch his/her idea to have it tested and implemented. Therefore on these grounds, this study posits that employee voice will mediate the relationship between servant leadership and innovative work behavior.

Hypothesis 4: Employee voice will mediate the relationship between Servant leadership and innovative work behavior.

\section{Methodology \\ 3.1 Data sample}

This empirical study utilized primary data collected from various public and private sector organizations in Ghana. Employing a simple random sampling technique (Kadilar \& Cingi, 2004) different organizations of people were selected giving everyone an equal chance of being nominated. Two distinct questionnaires were designed and randomly distributed to respondents in these organizations spreading through various functional departments to aid the study. A link to the questionnaire was generated and attached in an e-letter guaranteeing confidentially and anonymity. Prospective participants were made to understand that their decision to participate in the survey was absolutely voluntary and without monetary enticements. The e-letter was distributed via SMS, WhatsApp platforms, and through E-mails to supervisors and employees alike.

The first questionnaire was completed by leaders in supervisory and managerial capacity. This was aimed at measuring innovative work behavior and employee voice. As decided upon this was done to avert respondent bias on the part of the employees as self-rating questionnaires by employees can increase response/acquiescence bias (Chen \& Hou, 2016b) therefore may not accurately reflect the truest nature of employee voice or innovative work behavior. Similarly the same strategy was applied to the second questionnaire which was designed for the supervisors' corresponding subordinate(s) to measure servant leadership and psychological empowerment. Employees were granted to self-rate psychological empowerment because it would be very difficult for supervisors to know the true level to which employees were psychologically empowered. Likewise, to avert self-rating bias, employees rated theirs leader's servant leadership behavior.

Out of 320 distributed questionnaires, a total of 200 pieces of data was received from respondents, demonstrative of a low response rate. Nonetheless, 111 respondents were represented by males and 89 by females. 135 of the employees worked in the private sector whiles 65 comprised of the workforce in the public sector. Among them that participated in the questionnaire 144 were graduates, 40 postgraduates and 16 possessed high school diplomas. 146 of these employees had working experience ranging from 0-5 years, 27 of them had an experience of 6-10 years and 27 possessed 11 years and above working experience. Finally, 116 of the employees were between 20-29 years of age, 61 were within the range of 30-39 years and 23 were 40 years and above old.

\subsection{Measurement}

\subsubsection{Servant Leadership}

Employees were asked to rate how much they agree or disagree with the following statement about servant leadership in a seven-item global servant leadership questionnaire developed by Liden et al., (2015) was employed for this study. This was assessed using a seven-point Likert scale ranging from, 1- strongly disagree, 2- disagree, 3-somewhat disagree, 4- undecided, 5-Somewhat agree, 6- Agree, 7-Strongly agree) with the highest indicating strong servant leader behavior. A sample item is "My manager makes my career development a priority". The Cronbach Alpha for this study is 0.924 .

3.2.2 Employee voice

The ten items voice behavior measure scale developed by Liang et al., (2012) was employed in measuring employee voice. This was utilized in assessing supervisor ratings of their employees' voice behavior. A sample item included, "My employee, advise other coworkers against unpleasant behaviors that would impede job performance". The items were scored by a 5-point Likert scale rating (1- strongly disagree, 2- disagree, 3- neutral, 4- agree, 5 -strongly agree). The Cronbach Alpha for this study is 0.854 . 


\subsubsection{Innovative work behavior}

The 4-dimension measurement scale developed by Jong \& Hartog (2010) was used in the measurement of innovative work behavior. These dimensions include idea exploration, idea generation, idea championing, and idea implementation as subscales inspired by Janssen (2000), Kleysen and Street (2001), and Scott and Bruce (1994). The scale of measure consists of 10 items. The first 2 items evaluated idea exploration; the second 3 items examined idea generation, the third 2 items calculated idea championing, and the last 3 items measured idea implementation. The items were scored by a 5-point Likert scale rating (1- never, 2- rarely, 3- sometimes, 4- often, 5-always). A sample item included," How often does this employee pay attention to issues that are not part of his daily work?" The Cronbach Alpha for this study is 0.904 .

3.2.4 Data Analysis

The study employed a structural equation model (SEM) and linear regression in performing data analysis (Babin \& Anderson 2014). Pearson correlation was used to investigate the correlations existing between the variables of this present study. Confirmatory factor analysis was performed to measure the validity of the hypothesized model using the STATA 16 statistical software tool. Descriptive statistics, including mean and standard deviation, were generated for this study. Internal consistency was checked using Cronbach Alpha. The average variance extracted (AVE) approach to discriminant validity was also utilized to determine the independence of each construct (Fornell \& Larcker, 1981). Following Baron and Kenny (1986) mediation analysis approach, the mediating test was performed using the "medsem" command on STATA 16.

\section{Results}

Structural equation model estimations of the study

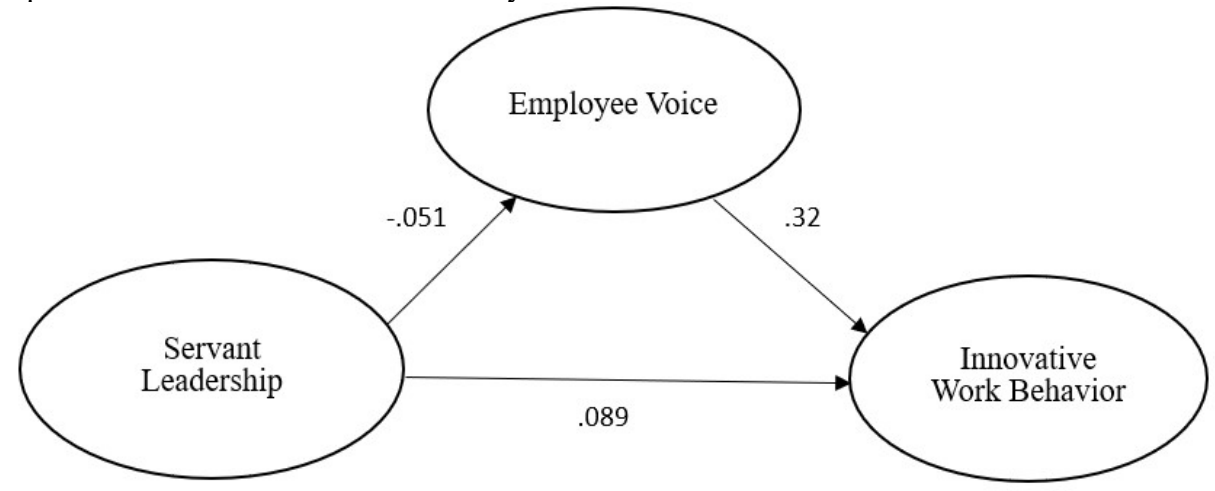

Figure 2 SEM estimation

The statistical fit for the model described in figure 2 is shown in Table 1 . The incremental fit indices, TLI, and CFI values, which are all $>0.92$, indicates a good model fit. The SRMR value of $0.052(<0.08)$ indicates a close-fitting model. Finally, an RMSEA of less than 0.8 indicates an appropriate match. Overall, the model is a close-fitting model that is suitable for research (Babin \& Anderson, 2014).

Table 1 Model Goodness of fit

\begin{tabular}{|l|l|l|l|}
\hline TLI & CFI & SRMR & RMSEA \\
\hline 0.948 & 0.959 & 0.052 & 0.061 \\
\hline
\end{tabular}

We tested for discriminant validity using the average variance extracted (AVE) analysis approach to ensure that the three constructs of this study (servant leadership, employee voice, and innovative work behavior) are distinct from one another. (Fornell \& Larcker, 1981). Table 2 presents that the latent constructs expressed by servant leadership, employee voice, and innovative work behavior are distinctive from one another and are not substantially connected. This is evidenced by the fact that each construct's discriminant values (square root of AVE) are larger than the correlation values between the constructs, confirming discriminant validity.

Table 2 Discriminant validity

\begin{tabular}{|l|l|l|l|}
\hline Latent Variables & Servant Leadership & Employee Voice & Innovative Work Behavior \\
\hline Servant Leadership & $\mathbf{0 . 6 9 5}$ & & \\
\hline Employee Voice & -0.077 & $\mathbf{0 . 7 9 7}$ & \\
\hline Innovative Work Behavior & 0.165 & 0.260 & $\mathbf{0 . 7 7}$ \\
\hline
\end{tabular}

Table 3 shows the correlation amongst the constructs of this research. This discloses the direction and strength of the relationships existing between the variables. The Pearson correlation generated by STATA 16, demonstrates that servant leadership and employee voice are positively and significantly correlated with innovative work behavior, finding significance at $\mathrm{p}<0.05, \mathrm{p}<0.01$. However servant leadership did not sustain a significant correlation with employee voice.

The Cronbach Alpha of each construct also proves to sustain a good internal consistency as reported by the 
scale reliability making the constructs valid for research, following verifications in early studies. The servant leadership scale reported 0.857 alpha reliability with 7 items. Employee voice scale recorded 0.854 alpha reliability with 10 scale items and innovative work behavior reported 0.904 displaying a very strong reliability scale with 10 items.

Table 3 Mean, Standard deviation, reliability and correlation of the study

\begin{tabular}{|l|l|l|l|l|l|}
\hline Variable & $\mathrm{M}$ & $\mathrm{SD}$ & 1 & 2 & 3 \\
\hline 1. Servant Leadership & 5.065 & 1.124 & $(0.857)$ & & \\
\hline 2. Employee Voice & 3.597 & 0.612 & -0.077 & $(0.854)$ & \\
\hline 3. Innovative Work Behavior & 3.428 & 0.645 & $0.165^{*}$ & $0.260^{* *}$ & $(0.904)$ \\
\hline
\end{tabular}

\subsection{Hypothesis Testing}

Hypothesis 1 (Servant leadership will positively influence innovative work behavior) was accepted by this study as the results in Table 4 demonstrates that servant leadership positively and significantly influenced employee innovative work behavior $(B=0.095, \mathrm{p}<0.05)$. Table 4 further indicates that about $3 \%$ of the variance in innovative work behavior is explained by servant leadership as revealed by the $\mathrm{R}^{\wedge} 2$ value.

Hypothesis 2 (Employee voice will positively influence innovative work behavior) was accepted by this study for the reason that employee voice positively and significantly influenced innovative work behavior $(B=0.247, p$ $<0.05)$ as demonstrated by Table 4 . The result also showed that about $7 \%$ of the variance of innovative work behavior is explained by voice behavior as revealed in Table 4 .

The empirical results shown in table 4 fails to reject hypothesis 3 (Servant leadership will positively influence employee voice) because servant leadership negatively and insignificantly impacted employee voice $(B=-0.042$, $\mathrm{p}>0.05$ ). The result also shows that about $0.6 \%$ of the variance of employee voice is explained by servant leadership shown in Table 4.

Table 4. Hypothesis testing - Linear regression

\begin{tabular}{|l|l|l|l|l|l|l|}
\hline Hypothesis & Dependent V. & Independent V. & $\begin{array}{l}\mathrm{B} \quad \begin{array}{l}\text { (unstandardized } \\
\text { coefficient) }\end{array} \\
\mathrm{R}^{\wedge} 2\end{array}$ & $\mathrm{p}$-value & Result \\
\hline H1 & InnovativeWB & Servant Leadership & 0.095 & 0.027 & 0.02 & Accepted \\
\hline H2 & InnovativeWB & Employee Voice & 0.247 & 0.068 & 0.000 & Accepted \\
\hline H3 & Employee Voice & Servant Leadership & -0.042 & 0.006 & 0.277 & Rejected \\
\hline
\end{tabular}

4.1.1 Mediation of Employee voice

According to the Baron \& Kenny (1986) mediation testing approach the results displayed in Table 5 proves that employee voice did not mediate the relationship between servant leadership and innovative work behavior. This is ascertained as the direct path connecting Innovative work behavior and voice is positively significant whiles the path from psychological empowerment to innovative voice behavior, though having a positive correlation failed to sustain statistical significance. The ratio of the indirect effect over the total effect (rit) displayed reveals that about $12 \%$ of the effect of servant leadership on innovative work behavior is mediated by voice behavior. The mediation model goodness of fit registered CFI- $0.959(>0.92)$, TLI- 0.948(>0.92), RMSEA- $0.061(<0.08)$ and SRMR- $0.052(<0.09)$, indicative of an acceptable model fit according to Babin \& Anderson, (2014) interpretation of SEM fit indices.

Table 5 Hypothesis Testing - Mediation analysis of Employee Voice

\begin{tabular}{|l|l|l|}
\hline Mediation of Voice & B (unstandardized coefficient) & p-value \\
\hline Path & -0.034 & 0.363 \\
\hline Voice: ServantLeadership (X->M) & 0.276 & 0.003 \\
\hline InnovativeWB: Voice (M->Y) & \\
\hline Ration of the direct effect over total effect (rit) $=0.124$ & \\
\hline
\end{tabular}

\section{Discussion}

The data result obtained by this study supported prior research that asserted that servant leadership is positively and strongly related to innovative work behavior (Faraz et al., 2019; Li et al., 2021). As a result, hypothesis 1 which proposed that servant leadership will positively influence employee innovative work behavior, was accepted by this study. The outcome of the linear regression performed also affirms that increasing servant leadership behavior will correspond to an increase in employee innovative work behavior.

In addition to the development of this empirical investigation, hypothesis 2 which postulated that employee voice will positively influence innovative work behavior, was supported by this study. According to Pearson's correlation analysis, the correlations were significant and positive. Therefore inferring that employee voice sustains the resilience to augment innovative work behavior. Thus an increase in employee voice behavior will 
potentially increase innovative work behavior.

The reason that servant leadership did not significantly influence employee voice as Hypothesis 3 proposed is suggestive of the fact that servant leadership in Ghana does not sustain adequate stature to positively affect employee voice behavior. This result however is at variance with the work of Yan \& Xiao (2016) whose work discovered that servant leadership was positively related to employee voice. This result is potentially influenced by the high power distant organization culture in Ghana, coupled with the reality of Ghana being considered as a least developing country (Silver, 2010). For this reason, organizational leadership in Ghana may not have developed strong servant leadership behavior yet to significantly and positively augment sound employee voice behavior. As noted by Aycan (2002) many developing countries compared to developed countries have limited resources including physical, technological and well qualified human resources. Thus making it challenging for the delivery of effective organizational leadership to prevail in Ghana. Yan \& Xiao's (2016) study on the impact of servant leadership on voice behavior was conducted with a Chinese dataset. Though China is also marked by a high power distance organizational culture (Yan \& Xiao, 2016), China is relatively, much more economically developed than Ghana is, for this reason clearly setting out the differences between these two economies and their potential organizational exploits.

Lastly, this research rejected hypothesis 4, which hypothesized that employee voice will mediate the effect of servant leadership on innovative work behavior. This was accrued to the empirical evidence that showed that employee voice (mediator) was insignificantly related to servant leadership (independent variable) as demonstrated by Table 5 , though it significantly related to innovative work behavior. According to the path model, servant leadership directly, positively and significantly influenced innovative work behavior and therefore the mediation of employee voice was not totally necessary as implied by the result. The ratio of the indirect effect over the total effect (rit) reported that employee voice well enough attempted to mediate the effect of servant leadership on innovative work behavior by about $12 \%$ but overall couldn't sustain enough aptitude for a complete mediation process. In the same manner following Baron and Kenny (1986), a full mediation can only be realized when the path model demonstrate a significant relationship between the mediator and both independent and dependent variables; as well as when there is an insignificant relationship between the independent and dependent constructs. A partial mediation can happen when the relationship between servant leadership (independent variable), employee voice (mediator) and innovative work behavior (dependent variable) are significantly related. Once the mediator insignificantly affect either of the independent or dependent variable, no mediation can take place.

\subsection{Research implication}

This study has helped to strengthen prior findings on the relevance of servant leadership, and employee voice as important antecedents to innovative work behavior (Faraz et al., 2019; Miao et al., 2020). Servant leadership behavior comprising of emotional healing, creating value for the community, conceptual skills, empowering helping followers grow and succeed putting followers first and having ethically increased employee abilities to explore, generate, champion and implement ideas for innovation.

Given the evidence of the research, this work would help managers and supervisors of organizations in Ghana have confidence in the outcome of putting on servant leadership behaviors for the purpose that it sustains the ability to increase innovative behaviors in employees which is critical for organizational innovation, productivity, and survival.

The deliberate attempt to increase innovative work behavior thereby innovation also means organizations necessitate the intentional creation of atmospheres (climate for innovation) for breeding and nurturing practical, innovative ideas to increase and materialize into workable models to make organizations in Ghana more competent in their dealings. This study also provides employers with the confidence that fostering employee voice in the workplace is important since it maintains the means of communicating creative ideas and serves as a means of resisting operational activities that may become an impediment to organizational progress.

Furthermore, it is key to note that front-line employees are able to observe and notice the practicality of things going right or wrong in any organization because they are mostly on the ground as compared to managers. Hence employees can serve as indispensable instruments in voicing out constructive suggestions or recommendations for better workplace functionality. This is chiefly because of their proximity to clients founded upon their daily interaction with them. Therefore employees can pick up tacit pieces of information on the job that can be astronomically beneficial for organizational growth when given the right attention.

\subsection{Limitation and future research}

There are various limitations to this study that should be noted when interpreting the results. To begin, the research hypothesis was investigated using a cross-sectional data; hence, this study reflects outcomes gained over a period of time, even though the idea was based on existing literature. For future studies on this topic, a longitudinal study approach would be advised for a deeper inspection in determining and giving additional empirical evidence between the variables. Also, future studies can consider conducting an empirical investigation examining the 
relationship between other forms of leadership on innovative work behavior by probing the mediation and moderation of employee voice, high power distance organizational culture and employee work engagement.

Secondly, the data was collected during a period in which part of the country was under quarantine as a result of stringent government rules requiring some organizations to work at home as part of a larger plan to combat the spread of Covid-19 in Accra, Ghana. This may have influenced the accuracy of the findings. We suggest that future studies concentrate on gathering data at a more fitting timeframe, possibly in a professional working setting. Lastly we also propose that future research includes a larger sample size that includes all 16 regions of Ghana.

\section{Conclusion}

In order to evaluate specific hypotheses while gaining significant insight into the mechanisms behind innovative work behavior in Ghana, this study tested a model of antecedents of innovative work behavior that included individual and contextual factors. The development process of this research discovered that servant leadership, and employee voice successfully sustained a positive and significant influence on employee innovative work behavior. Through the examination and analysis of the cross-sectional data, this study demonstrated that servant leadership was not significantly related to employee voice among Ghanaian organizations. Consequently, this developed to the failure of employee voice in successfully mediating the impact of servant leadership on innovative work behavior.

\section{References}

Afsar, B., Shahjehan, A., Shah, S. I., \& Wajid, A. (2019). The mediating role of transformational leadership in the relationship between cultural intelligence and employee voice behavior: A case of hotel employees. International Journal of Intercultural Relations, 69, 66-75. https://doi.org/10.1016/j.ijintrel.2019.01.001

Amabile, T. . (1996). Creativity and Innovation in Organizations. Harvard Business School Background Note.

Amabile, T. M. (1983). The Social Psychology of Creativity: A Componential Conceptualization. Journal of Personality and Social Psychology, 45, 357-376. https://doi.org/http://dx.doi.org/10.1037/00223514.45.2.357

ARTHUR, N. A. D. (2016). The Influence Of Leadership Styles On Employee Creativity In Ghana's Telecommunication Industry. Business and Management Studies, 2(1), 23-34. http://etd.uum.edu.my/2605/

Asiedu-Appiah F., Agyapong A., L. T. R. (2017). Leadership in Ghana. In: LEAD: Leadership Effectiveness in Africa and the African Diaspora. Palgrave Studies in African Leadership.Palgrave Macmillan, New York. https://doi.org/https://doi.org/10.1057/978-1-137-59121-0_6

Babin, B. J., \& Anderson, R. E. (2014). on Multivariate Data Analysis Joseph F . Hair Jr. William C. Black Seventh Edition.

Barbuto, J. E., \& Wheeler, D. W. (2006). Scale Development and Construct Clarification of Servant Leadership. $\begin{array}{lllll}\text { Group } \quad \& \quad \text { Management, } & 31, & 300-326 .\end{array}$ https://doi.org/https://doi.org/10.1177/1059601106287091

Baron, R.M. and Kenny, D. (1986). The Moderator-Mediator Variable Distinction in Social Psychological Research: Conceptual, Strategic, and Statistical Considerations. Journal of Personality and Social Psychology, 51, 1173-1182. https://doi.org/http://dx.doi.org/10.1037/0022-3514.51.6.1173

BLAKEMORE, E. (2020). How Nelson Mandela fought apartheid - and why his work is not complete. National Geography. https://www.nationalgeographic.com/history/article/nelson-mandela-fought-apartheid-worknot-complete

Burkus, D. (2010). Servant Leadership Theory. https://davidburkus.com/2010/04/servant-leadership-theory/

De Jong, J., \& Den Hartog, D. (2010). Measuring innovative work behaviour. Creativity and Innovation Management, 19(1), 23-36. https://doi.org/10.1111/j.1467-8691.2010.00547.x

Detert, J.R. and Burris, E. R. (2007). Leadership Behavior and Employee Voice: Is the Door Really Open? Academy of Management, 50, 869-884.

Detert, J. R., \& Burris, E. R. (2007). Leadership behavior and employee voice: Is the door really open? Academy of Management Journal, 50(4), 869-884. https://doi.org/10.5465/AMJ.2007.26279183

Erdogan, B., \& Bauer, T. N. (2015). Leader-Member Exchange Theory. International Encyclopedia of the Social \& Behavioral Sciences: Second Edition, October 2017, 641-647. https://doi.org/10.1016/B978-0-08-0970868.22010-2

Eva, N., Robin, M., Sendjaya, S., van Dierendonck, D., \& Liden, R. C. (2019). Servant Leadership: A systematic review and call for future research. The Leadership Quarterly, 30(1), 111-132. https://doi.org/10.1016/J.LEAQUA.2018.07.004

Fornell, C., \& Larcker, D. F. (1981). Evaluating Structural Equation Models with Unobservable Variables and Measurement Error. Journal of Marketing Research, 18(1), 39. https://doi.org/10.2307/3151312

Frieder, R. E., Hochwarter, W. A., \& DeOrtentiis, P. S. (2015). Attenuating the negative effects of abusive supervision: The role of proactive voice behavior and resource management ability. Leadership Quarterly, 
26(5), 821-837. https://doi.org/10.1016/j.leaqua.2015.06.001

Gentile, M. C. (2012). Values-driven leadership development: Where we have been and where we could go. Organisation Management Journal, 9(3), 188-196. https://doi.org/10.1080/15416518.2012.708854

Greenleaf, R. K. (1970). The servant as leader. In Robert K. Greenleaf Publishing Center.

Hale, J. R., \& Fields, D. L. (2007). Exploring servant leadership across cultures: A study of followers in Ghana and the USA. Leadership, 3(4), 397-417. https://doi.org/10.1177/1742715007082964

Jong, J. P. J. D., \& Hartog, D. N. Den. (2008). Innovative Work Behavior : Measurement and Validation. Scientific Analysis of Entrepreneurship and SMEs, November, 1-27.

Keith Miller. (2021). Coercive Leadership Style Advantages, Disadvantages and Characteristics. FutureofWorking.com

Kenny, D. A. (2020). Measuring model fit. http://davidakenny.net $/ \mathrm{cm} /$ fit.htm

Kremer, H., Villamor, I., \& Aguinis, H. (2019). Innovation leadership: Best-practice recommendations for promoting employee creativity, voice, and knowledge sharing. Business Horizons, 62(1), 65-74. https://doi.org/10.1016/j.bushor.2018.08.010

Krupah, E. K. (2021). The Effect of Psychological Empowerment on Innovative Work Behavior: The Mediating Role of Employee Voice. European Journal of Business and Management, 13(18), 92-104. https://doi.org/10.7176/ejbm/13-18-10

Laub, J. (2004). Defining Servant Leadership: a Recommended Typology for Servant Leadership'. Paper presented at the Servant Leadership Research Roundtable. Regent University, Virginia Beach, Virginia, August.

Lee, Y., \& Kim, J. (2021). Cultivating employee creativity through strategic internal communication: The role of leadership, symmetry, and feedback seeking behaviors. Public Relations Review, 47(1), 101998. https://doi.org/10.1016/J.PUBREV.2020.101998

Leunendong, M. (2020). Paternalistic Leadership Guide: Definition, Qualities, Pros\&Cons,Examples. https:/www.cleverism.com/paternalistic-leadership-guide/

Li, F., Liu, B., Lin, W., Wei, X., \& Xu, Z. (2021). How and when servant leadership promotes service innovation: A moderated mediation model. Tourism Management, 86, 104358. https://doi.org/10.1016/J.TOURMAN.2021.104358

Liang, J., Farh, C. I. C., \& Farh, J. L. (2012). Psychological antecedents of promotive and prohibitive Voice: A two-wave examination. Academy of Management Journal, 55(1), 71-92. https://doi.org/10.5465/amj.2010.0176

Liden, R. C., Wayne, S. J., Meuser, J. D., Hu, J., Wu, J., \& Liao, C. (2015). Servant leadership: Validation of a short form of the SL-28. The Leadership Quarterly, 26(2), 254-269. https://doi.org/10.1016/J.LEAQUA.2014.12.002

Liden, R. C., Wayne, S. J., Zhao, H., \& Henderson, D. (2008). Servant leadership: Development of a multidimensional measure and multi-level assessment. Leadership Quarterly, 19(2), 161-177. https://doi.org/10.1016/j.leaqua.2008.01.006

Maxwell, J. C. (2007). The 21 Irrefutable Laws of Leadership.

Maynes, T. D., \& Podsakoff, P. M. (2014). Speaking more broadly: An examination of the nature, antecedents, and consequences of an expanded set of employee voice behaviors. Journal of Applied Psychology, 99(1), 87-112. https://doi.org/10.1037/a0034284

Müceldili, B., Turan, H., \& Erdil, O. (2013). The Influence of Authentic Leadership on Creativity and Innovativeness. Procedia - Social and Behavioral Sciences, 99, 673-681. https://doi.org/10.1016/j.sbspro.2013.10.538

Nair, R., Veeresh, N., \& Eagar, R. (2011). Innovation for economic diversification - experience from the Middle East. Knowledge $4 \mathrm{All}, 2$, 1-8. http://www.knowledge4all.com/en/237/Publications/Innovation-forEconomic-Diversification-Experience-from-the-Middle-East

Nikolaou, I., Gouras, A., Vakola, M., \& Bourantas, D. (2007). Selecting Change Agents: Exploring Traits and Skills in a Simulated Environment. Journal of Change Management, 7(3-4), 291-313. https://doi.org/10.1080/14697010701779173

Northouse, P. G. (2019). Leadership.

Nugent, J. De. (2018). Napoleon on Jesus. https://www.johndenugent.com/napoleon-on-jesus/

Oduro, S., \& Nyarku, K. M. (2018). Incremental Innovations in Ghanaian SMEs: Propensity, Types, Performance and Management Challenges. Asia-Pacific Journal of Management Research and Innovation, 14(1-2), 10 21. https://doi.org/10.1177/2319510x18810034

Peter G. Northouse. (2019). Leadership Theory and Practice 8TH Edition Servant Leadership.

Purdur University Global. (2020). What is Servant Leadership. Purdur Global. https://www.purdueglobal.edu/blog/business/what-is-servant-leadership

Redmond, M. V. (2015). "Social Exchange Theory." English Technical Reports and White Papers., 5. 
http://lib.dr.iastate.edu/engl_reports/5

Ruiz-Palomino, P., \& Zoghbi-Manrique-de-Lara, P. (2020). How and when servant leaders fuel creativity: The role of servant attitude and intrinsic motivation. International Journal of Hospitality Management, 89, 102537. https://doi.org/10.1016/J.IJHM.2020.102537

Sanda, A., \& Arthur, N. A. D. (2017). Relational impact of authentic and transactional leadership styles on employee creativity: The role of work-related flow and climate for innovation. African Journal of Economic and Management Studies, 8(3), 274-295. https://doi.org/10.1108/AJEMS-07-2016-0098

Scott, S. G., \& Bruce, R. A. (1994). Determinants of Innovative Behavior : A Path Model of Individual Innovation in the Workplace Author ( $\mathrm{s}$ ): Susanne G . Scott and Reginald A . Bruce Published by: Academy of Management Stable URL : http://www.jstor.org/stable/256701 REFERENCES Linked refe. The Academy of Management Journal, 37(3), 580-607.

Shafi, M., Zoya, Lei, Z., Song, X., \& Sarker, M. N. I. (2020). The effects of transformational leadership on employee creativity: Moderating role of intrinsic motivation. Asia Pacific Management Review, 25(3), 166176. https://doi.org/10.1016/j.apmrv.2019.12.002

Shalley, C. E., Zhou, J., \& Oldham, G. R. (2004). The effects of personal and contextual characteristics on creativity: Where should we go from here? Journal of Management, 30(6), 933-958. https://doi.org/10.1016/j.jm.2004.06.007

Spears, L. C. (2010). Character and Servant Leadership: Ten Characteristics of Effective, Caring Leaders. Journal of Virtues \& Leadership, 1(1).

StudiousGuy. (2021). Paternalistic Leadership Style: Types and Examples. https://studiousguy.com/paternalisticleadership-style-types-examples/

Van Dyne, L., \& LePine, J. A. (1998). Helping and voice extra-role behaviors: Evidence of construct and predictive validity. Academy of Management Journal, 41, 108-119. https://doi.org/10.2307/256902

Walumbwa, F. O., Morrison, E. W., \& Christensen, A. L. (2012). (). Ethical leadership and group in-role performance: The mediating roles of group conscientiousness and group voice. , (5), . The Leadership Quarterly, 23(5), 953-964. https://doi.org/10.1016/j.leaqua.2012.06.004

Woodman, R. W. (1993). Toward a Theory of Organizational Creativity Author ( s ): Richard W . Woodman, John E. Sawyer and Ricky W. Griffin Published by: Academy of Management Stable URL: https://www.jstor.org/stable/258761 REFERENCES Linked references are available on JSTO. The Academy of Management Review, 18(2), 293-321.

Yan, A., \& Xiao, Y. (2016). Servant leadership and employee voice behavior: a cross-level investigation in China. SpringerPlus, 5(1). https://doi.org/10.1186/s40064-016-3264-4

Yoshida, D. T., Sendjaya, S., Hirst, G., \& Cooper, B. (2014). Does servant leadership foster creativity and innovation? A multi-level mediation study of identification and prototypicality. Journal of Business Research, 67(7), 1395-1404. https://doi.org/10.1016/J.JBUSRES.2013.08.013

YuSheng, K., \& Ibrahim, M. (2020). Innovation Capabilities, Innovation Types, and Firm Performance: Evidence From the Banking Sector of Ghana. SAGE Open, 10(2). https://doi.org/10.1177/2158244020920892

Zhang, X., Gloor, P. A., \& Grippa, F. (2013). Measuring creative performance of teams through dynamic semantic social network analysis. International Journal of Organisational Design and Engineering, 3(2), 165. https://doi.org/10.1504/ijode.2013.057014

Zhou, J. and George, J. M. (2001). When job dissatisfaction leads to creativity: Encouraging the expression of voice. Academy of Management Journal, 44, 682-696. 